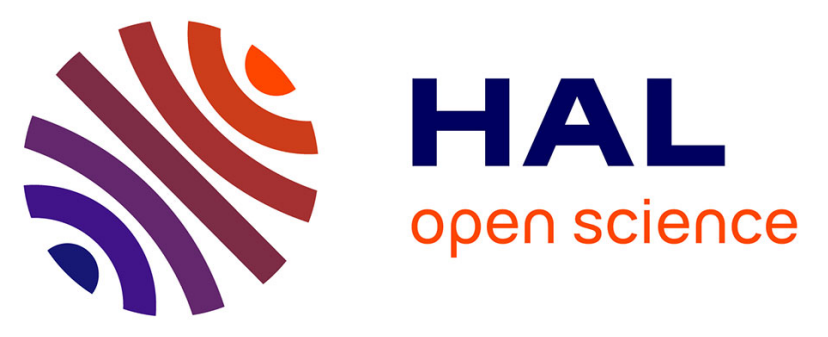

\title{
Subcellular Chemical Imaging: New Avenues in Cell Biology.
}

Johan Decelle, Giulia Veronesi, Benoit Gallet, Hryhoriy Stryhanyuk, Pietro

Benettoni, Matthias Schmidt, Rémi Tucoulou, Melissa Passarelli, Sylvain Bohic, Peta Clode, et al.

\section{To cite this version:}

Johan Decelle, Giulia Veronesi, Benoit Gallet, Hryhoriy Stryhanyuk, Pietro Benettoni, et al.. Subcellular Chemical Imaging: New Avenues in Cell Biology.. Trends in Cell Biology, 2020, 30 (3), pp.173-188. 10.1016/j.tcb.2019.12.007 . hal-02492213

\section{HAL Id: hal-02492213 \\ https://hal.science/hal-02492213}

Submitted on 23 Nov 2020

HAL is a multi-disciplinary open access archive for the deposit and dissemination of scientific research documents, whether they are published or not. The documents may come from teaching and research institutions in France or abroad, or from public or private research centers.
L'archive ouverte pluridisciplinaire HAL, est destinée au dépôt et à la diffusion de documents scientifiques de niveau recherche, publiés ou non, émanant des établissements d'enseignement et de recherche français ou étrangers, des laboratoires publics ou privés.

\section{()ㅜ) $\Theta$}

Distributed under a Creative Commons Attribution - NoDerivatives| 4.0 International 


\section{Subcellular chemical imaging: new avenues in cell biology}

2 Johan Decelle ${ }^{1 *}$, Giulia Veronesi ${ }^{2,3}$, Benoit Gallet ${ }^{4}$, Hryhoriy Stryhanyuk ${ }^{5}$, Pietro Benettoni ${ }^{5}$, Matthias

3 Schmidt $^{5}$, Rémi Tucoulou ${ }^{3}$, Melissa Passarelli ${ }^{6}$, Sylvain Bohic ${ }^{3,7}$, Peta Clode ${ }^{8,9}$, Niculina Musat $^{5}$

4 Affiliations:

5 1- Cell and Plant Physiology Laboratory, University Grenoble Alpes, CNRS, CEA, INRA, IRIG, Grenoble, France.

6 2- Chemistry and Biology of Metals Laboratory, Université Grenoble Alpes, CNRS, CEA, IRIG, Grenoble, France.

7 3- ESRF - The European Synchrotron, Grenoble, France.

8 4- Institut de Biologie Structurale, Université Grenoble Alpes, CNRS, CEA; Grenoble, France.

9 5- Helmholtz Centre for Environmental Research - UFZ, Department of Isotope Biogeochemistry, Leipzig, Germany.

10 6- Ecole Polytechnique Fédérale de Lausanne (EPFL), Laboratory for Biological Geochemistry, Lausanne, Switzerland.

11 7- INSERM - UA7 - Synchrotron Radiation for Biomedicine, STROBE, University Grenoble Alpes, Grenoble, France.

12 8- The Centre for Microscopy Characterisation and Analysis, The University of Western Australia, Crawley, Australia.

13 9- UWA School of Biological Sciences, The University of Western Australia, Crawley, Australia.

Keywords: chemical imaging, correlative microscopy, electron microscopy, elemental imaging, X-ray fluorescence, SIMS

*Correspondence: johan.decelle@univ-grenoble-alpes.fr

Abstract

To better understand the physiology and acclimation capability of a cell, one of the great challenges of the future is to access the interior of a cell and unveil its chemical landscape (composition and distribution of elements and molecules). Chemical imaging has greatly improved in sensitivity and spatial resolution to visualize and quantify nutrients, metabolites, toxic elements, and drugs in single cells at the subcellular level. This review aims at presenting the current potential of these emerging imaging technologies and guiding biologists towards a strategy for interrogating biological processes at the nanoscale. We also describe different solutions to combine multiple integrative subcellular imaging across different disciplines. 
New avenues for the subcellular exploration of the cell

The advent of electron microscopy in the mid 1900s was a formidable tool for the detailed exploration of a cell's structure at nanoscale resolution. Nowadays, a key challenge in cell biology is to understand the activity and function of organelles and cellular compartments, and their role in the metabolism and physiology of a cell. Omics bulk analyses (e.g. transcriptomics, metabolomics) have greatly improved our understanding on cellular mechanisms, but only provide averaged information of extracted molecules from numerous lysed cells. Hence, spatial information at the subcellular level is a missing dimension to fully interpret the phenotypic state of a cell and assess heterogeneity in a population. Chemical imaging techniques (see Glossary) are now able to reveal the chemical landscape of cells (i.e. the composition and distribution of elements and molecules) at the subcellular level without the need to add or genetically encode fluorescent labels. Probing the elemental and molecular composition in organelles and subcellular structures can reveal fundamental information about the function and physiology of a cell in response to different conditions. The subcellular distribution of some elements (e.g. the macronutrients $\mathrm{N}, \mathrm{P}, \mathrm{S}$ ), which are essential building blocks of biomolecules (e.g. DNA, proteins, lipids), can reflect the metabolic roles and needs of organelles [1]. Trace metals (e.g. $\mathrm{Fe}, \mathrm{Cu}, \mathrm{Zn}$ ) play a fundamental role in different biochemical functions of the cell, and their homeostasis and compartmentalization need to be tightly controlled to avoid cell death and severe pathologies. More particularly, metals are key players in parasitic and viral infections, cancer cells, and neurodegenerative diseases [2]. In the biomedical field, the increasing human exposure to exogenous compounds (e.g. metal-based nanoparticles, toxic elements) and use of therapeutic drugs, call for imaging techniques to visualize their fate in tissues and cells, and assess their toxicity and impact on the homeostasis of native elements [3,4]. In addition to elements, the localization of metabolites (e.g. sugars, lipids) in cells is also essential to fully understand metabolic processes. Therefore, subcellular mapping of elements and metabolites is becoming indispensable to investigate the physiology and metabolism of healthy and diseased cell types, understand cellular interactions in tissues or with beneficial cells (e.g. symbioses) and pathogens (e.g. viral or bacterial infection), and their adaptive response to abiotic stresses.

Recent technological progress in chemical imaging has substantially improved sensitivity and spatial resolution, allowing disentangling of cellular compartments in a single cell. However, the multiplicity of these complex imaging techniques requires guidance for non-specialists. An 
overview of the chemical imaging techniques currently available is therefore needed to help biologists integrating the subcellular scale in their studies while being aware of their potential and limitations. Each chemical imaging platform presents experimental specifications that make them more sensitive to some elements or molecules, so different platforms need to be combined to have a comprehensive view of the chemical landscape of a cell. Moreover, since chemical imaging generally provides limited information on the cell ultrastructure, electron microscopy (EM) is often required to interpret the intracellular localization of elements and molecules. Correlation between light microscopy and EM (CLEM) is well established [5,6], but correlation between EM and chemical imaging is less developed. Bridging the data acquired with different high-resolution imaging strategies is the next challenge and will make correlative subcellular imaging a new powerful research tool towards integrative cell biology.

This review aims at presenting the potential and limitations of state-of-the-art chemical imaging techniques for non-specialists who seek to obtain chemical information at the subcellular level. We aim to guide biologists to the appropriate imaging technique and associated sample preparation to visualize and quantify elements or biomolecules in cells. We also summarize the new developments for correlative subcellular imaging (Figure 1, Key Figure), highlight the role of such combinatory techniques to disentangle biochemical processes of a cell and discuss future challenges and directions in the field.

\section{$\underline{\text { Potential and limitations of subcellular chemical imaging platforms and }}$}

\section{required sample preparation}

Multiple chemical imaging instruments are capable of visualizing the molecular, elemental, and isotopic composition of a cell with high lateral resolution [7]. These microscopes are generally equipped with a high-energy, and focused primary beam of electrons, protons, photons, or ions that raster across the surface of the sample and obtain quantitative information in a spatially resolved manner (Box 1). The instrument and experimental setup need to be carefully chosen according to the research question and the target elements or molecules of interest. Here we focus on the key methodologies that are routinely being used to provide subcellular information. Lower resolution technologies (e.g. MALDI, LA-ICP-MS) will not be discussed in detail here (see review $[8])$. 
X-ray fluorescence microscopy relies on the excitation of core electrons of atoms that leads to X-ray emissions, which are specific to elements in the sample (see Glossary and Box 1). The primary probe determines the technique: electrons in Energy Dispersive X-ray Spectrometry (S/TEM-EDS); protons in particle-induced X-ray emission (PIXE), synchrotron-generated photons in synchrotron X-Ray Fluorescence (S-XRF) imaging. These analytical techniques can be used to visualize and quantify the distribution of macronutrients (e.g. P, S), key trace elements (e.g. $\mathrm{Mn}, \mathrm{Fe}, \mathrm{Cu}, \mathrm{Zn}, \mathrm{Se}$ ), toxic heavy metals (e.g. $\mathrm{Hg}, \mathrm{Pb}$ ), and pharmacological compounds (e.g. organometallic compounds based on $\mathrm{Pt}$, Ir, Os, Ru). S/TEM-EDS can provide the highest spatial resolution (sub-nanometre in TEM) with sensitivity of $\sim 1000 \mathrm{ppm}\left(1 \mathrm{mg}^{-1} \mathrm{~g}^{-1}\right.$ [9]. Compared to this, PIXE is less spatially resolved (sub-micron) but is more sensitive (ppm range) [7]. But overall, synchrotron X-ray Fluorescence (S-XRF) provides arguably the best combination of high spatial resolution capabilities (down to few $10 \mathrm{~nm}$ ) and high sensitivity (sub-ppm) to light and heavy elements (Figure 2, Box 1) [10,11]. S-XRF has allowed mapping and quantification of metals, such as Fe, Zn, Cu in microalgal and human cells [12-14], as well as silica, drugs, organometallic molecules, and titanium oxide nanoparticles in cancer cells [2,15-19]. In combination with XRF imaging, X-ray Absorption Spectroscopy (XAS) can be performed in order to reveal the chemical speciation of a target element. XAS has disclosed the chemical transformations of indium-based nanocrystals, or of osmium-based anticancer drugs in cancer cells [20,21]. The modulations of the XAS spectra also allowed mapping the distribution of different chemical states of S (e.g. sulfate esters and inorganic sulfate) in a biological tissue, in order to understand their role in cell differentiation [22].

Secondary ion mass spectrometry (SIMS) instruments are based on the analysis of mass of elements and molecules (see Glossary). Secondary ions are sputtered away from the topmost layer of a sample by a focused primary ion beam and analyzed in a mass spectrometer (Box 1). NanoSIMS is a SIMS instrument particularly suitable for probing macronutrients and metals in cells at a lateral resolution down to $50 \mathrm{~nm}$ (Figure 2) [23-26]. For instance, P, S, Ca, Fe, Zn, Mn, and $\mathrm{Cu}$ have been mapped in cells [12,25,27,28]. Morphological features of the cell can be revealed by secondary electron signal (only in negative extraction mode), and from different secondary ions, such as cyanide $\left({ }^{12} \mathrm{C}^{14} \mathrm{~N}^{-}\right)$and phosphorous $\left({ }^{31} \mathrm{P}^{-}\right)$showing the overall shape and internal compartments of the cell, and the nucleus, respectively. The high mass-resolving power of nanoSIMS can also unveil the isotopic composition of a cell (i.e. being able to distinguish between 
$122{ }^{12} \mathrm{C}^{15} \mathrm{~N}$ and ${ }^{13} \mathrm{C}^{14} \mathrm{~N}$ ), and so is highly suitable for stable isotope probing (SIP) [29,30]. SIP123 nanoSIMS allows for quantitation of metabolic activities at the subcellular level (e.g. 50 - $100 \mathrm{~nm}$ ), 124 such as $\mathrm{C}$ and $\mathrm{N}$ assimilation [31-34]. This technique has been used to understand nutrient 125 exchange between cells in symbiotic, pathogenic and virus-host interactions [35-40] and the 126 localization of drug compounds in human cells [41] (Figure 2).

127 With the ToF-SIMS (Time-of-Flight-SIMS; see Glossary and Box 1), molecular information can 128 be obtained since the ion probe (polyatomic or gas cluster) is less destructive than in nanoSIMS 129 (monoatomic). The softer ionization conditions, as compared to nanoSIMS, allow for spatially 130 resolved analysis of large molecular fragment species within the range of 1 to 1000 Da with a 131 typical lateral resolution of $100 \mathrm{~nm}-5 \mu \mathrm{m}$. Different analysis modes exist: spectrometry mode to 132 get high mass resolution, imaging mode to get high lateral resolution, and delayed extraction mode 133 to combine high mass resolution (10000 MRP) with a high lateral resolution (400 nm) [42]. 134 Delayed extraction is now widely used to image organic samples and lately was shown to achieve 135 a $108 \mathrm{~nm}$ lateral resolution to visualize single particle in algal biofilms [43,44]. ToF-SIMS is a 136 useful method for studying small molecules [45-47] and lipids in cells, especially in lipid-related 137 diseases, such as cancer, Duchenne muscular dystrophy and atherosclerosis (Figure 2) [48,49].

\section{Box 1. Principles of subcellular chemical imaging techniques}

Figure_BOX1 

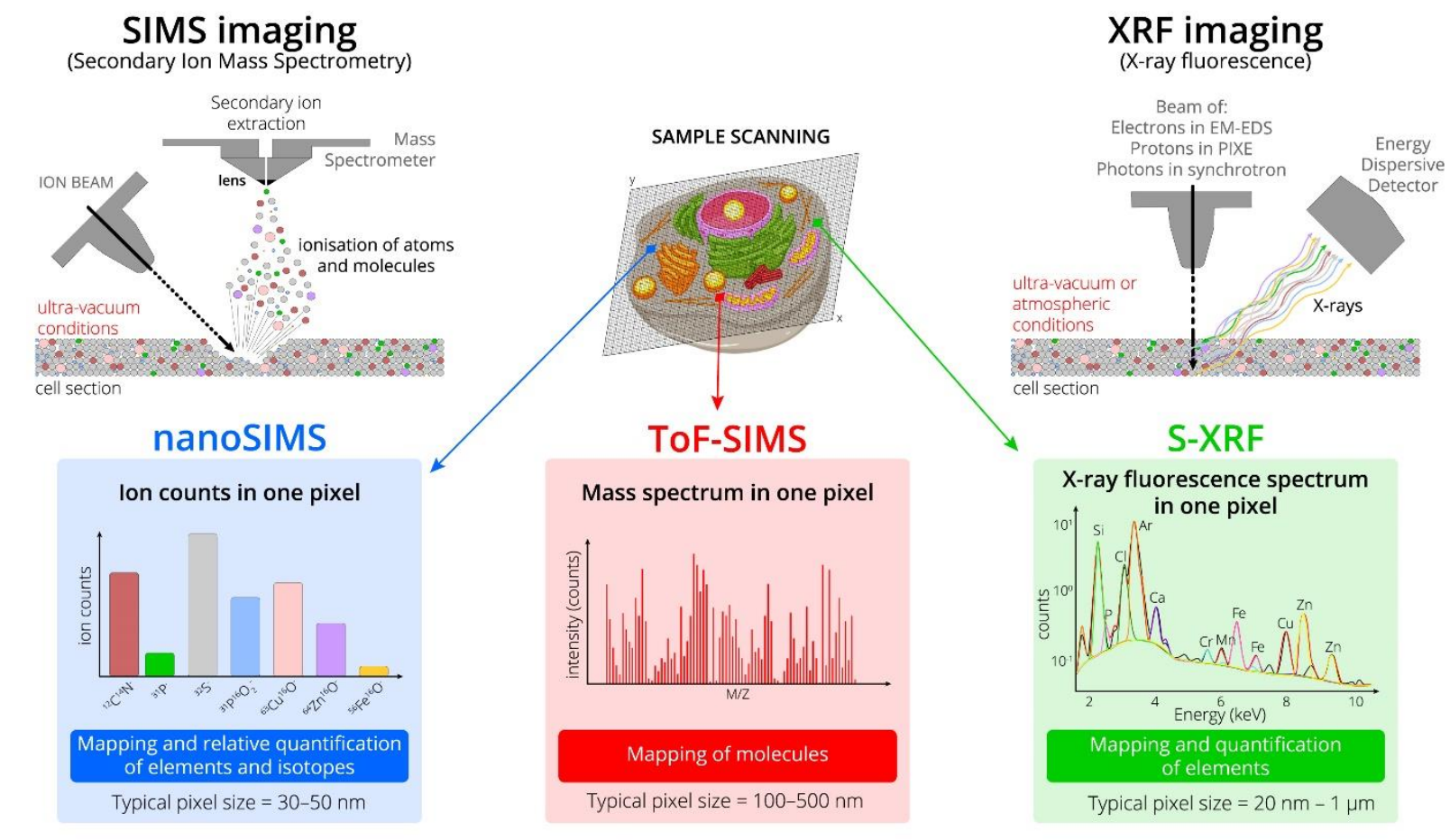

* X-ray fluorescence (XRF) relies on the photoelectric effect occurring when an X-ray photon is absorbed by an atom: a photo-electron is ejected from a core orbital of the excited atom leaving a vacancy which is then filled by another electron from a higher orbital. This is followed by the emission of a fluorescence X-ray photon whose energy is characteristic of the element. XRF acquisition is often performed by scanning the sample and energy dispersive detectors collect and measure the emitted fluorescence spectrum in each pixel, unveiling the elemental composition. The beam size determines the spatial resolution, from $10 \mathrm{~nm}$ up to $1 \mu \mathrm{m}$. For a thin sample, the intensity of the fluorescence is proportional to the concentration of the elements, which can be calculated using thin standards of known concentration.

* SIMS (Secondary Ion Mass Spectrometry): Upon impact of a focused ion beam, sample material is sputtered and about $1 \%$ of ejected material is ionized. In nanoSIMS, these ions are extracted in negative or positive modes into a mass spectrometer and separated according to their mass-to-charge ratio (m/z) in the magnetic sector of the mass analyzer. Simultaneous detection of up to 7 secondary ion species (monoatomic ions or small molecular fragments of up to 4-6 atoms) can be achieved. The ion beam can 
scan a predefined surface area of the cell, therefore providing color-coded cartography of ion counts per pixel. Note that the charge compensation (i.e., compensating the build-up charge on non-conductive surfaces) is available only in negative extraction mode. Therefore, coating the sample surface with a conductive metal $(\sim 10 \mathrm{~nm})$ is mandatory to overcome this limitation in positive extraction mode.

In ToF-SIMS (Time-of-Flight Secondary Ion Mass Spectrometry), the ejection and ionization of material relies on a lower ion beam fluence and less destructive cluster ion sources compared to nanoSIMS. With new cluster ion sources $\left(\mathrm{Bi}_{\mathrm{n}}, \mathrm{Ar}_{\mathrm{n}}, \mathrm{Au}_{\mathrm{n}}, \mathrm{C}_{60}\right)$, ToF-SIMS provides the possibility of minimizing molecular damages while maximizing molecular ion yields. Small organic molecules within range of 1 to $\sim 1000 \mathrm{Da}$ can be detected with a lateral resolution of around a micron on biological material. The pulsed operation mode of the primary ion gun and its $45^{\circ}$ mounting geometry allows for charge compensation in both extraction polarities while employing the same primary ion species. Yet, the $45^{\circ}$ geometry can cause shadowing and lateral displacement effect upon depth profiling or when analyzing a surface with a pronounced topography.

140 Seeing is believing, but what we see critically depends on the sample preparation. Sample 141 preparation is one of the most fundamental steps - and should aim to preserve cells as close as 142 possible to their native state - the Holy Grail in cell biology. The ideal method is the one that fixes and conserves both the ultrastructure of the cell and its native chemical composition (Box 2).

144 However, sample preparation is highly specific to both the sample and instrument(s) being used, 145 and compromises have to be made at each experiment (Table 1).

\section{Box 2. Sample preparation for subcellular imaging}

Figure Box 2 


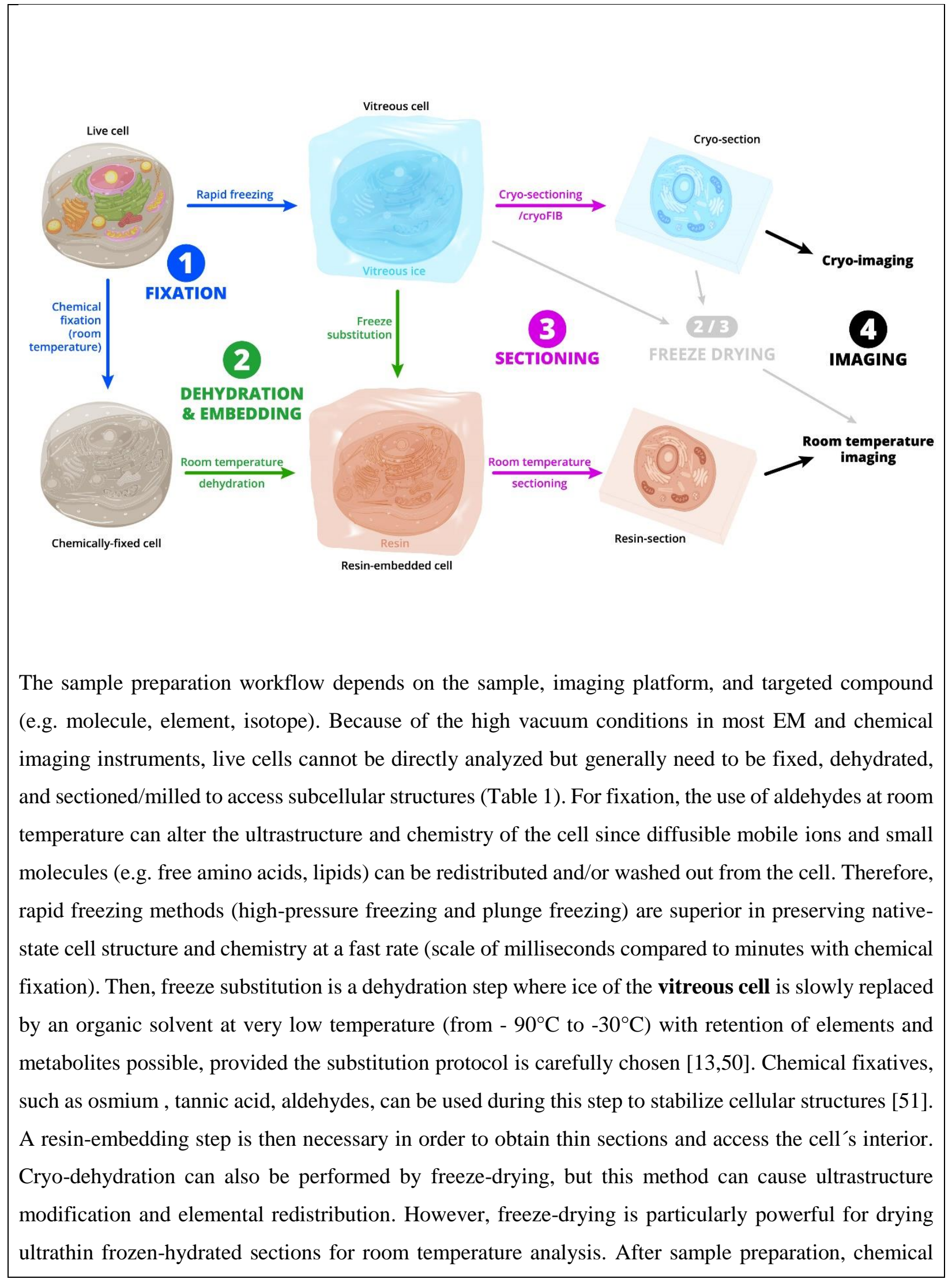


preservation of the cell can be assessed by visualizing the most diffusible elements $\left(\mathrm{K}^{+}, \mathrm{Na}^{+}, \mathrm{Ca}^{2+}, \mathrm{Cl}^{-}\right)$ that move rapidly across membranes and within the cytoplasm, thus representing a relevant rule-ofthumb criterion for chemical preservation [52]. Overall, it remains difficult to be certain that the chemical environment within a cell is a true representation of normal physiology, and each step of the preparation can be debatable. We recommend more methodological development and comparisons in the future to optimize sample preparation and assess putative artefacts. This is a challenge since access to cuttingedge microscopes is generally difficult for that methodological purpose. Compared to freeze-substituted and resin-embedded cells, analyzing frozen-hydrated cells (or vitreous cells) is obviously superior for chemical preservation (Table 1). However, this leads to many challenges that need to be tackled in the future (further discussed in this review): i) cryo-sectioning, ii) the need for a cryo-transfer system and a cryo-stage in the imaging platform, iii) difficulty to undertake correlative studies across different platforms; iv) inherent lack of contrast for sample visualization.

\begin{tabular}{|c|c|c|c|}
\hline $\begin{array}{c}\text { Sample } \\
\text { preparation steps }\end{array}$ & Strategy & Pros & Cons \\
\hline \multirow{3}{*}{ Fixation of cell } & Chemical fixation & $\begin{array}{l}\text { Easy to use in the field or for } \\
\text { pathogenes (human parasites) }\end{array}$ & $\begin{array}{l}\text { Ultrastructure and chemical } \\
\text { composition can be greatly } \\
\text { modified }\end{array}$ \\
\hline & $\begin{array}{l}\text { Cryo-fixation under high } \\
\text { pressure }\end{array}$ & $\begin{array}{l}\text { Excellent preservation of the } \\
\text { ultrastructure and chemistry of } \\
\text { the cell }\end{array}$ & $\begin{array}{c}\text { Thickness of the sample } \\
\text { must be less than } 200 \mu \mathrm{m} \text {, } \\
\text { requires bulky laboratory- } \\
\text { based equipment }\end{array}$ \\
\hline & $\begin{array}{l}\text { Cryo-fixation with plunge } \\
\text { freezing in a liquid cryogen }\end{array}$ & $\begin{array}{c}\text { Can be done in the field or the } \\
\text { laboratory }\end{array}$ & $\begin{array}{l}\text { Maximum sample thickness } \\
\text { to maintain vitreous ice } \\
\text { formation is } \sim 5 \mu \mathrm{m} \text {, some ice } \\
\text { crystal formation in thicker } \\
\text { samples }\end{array}$ \\
\hline \multirow{3}{*}{ Dehydration } & $\begin{array}{l}\text { Chemical dehydration at } \\
\text { room temperature }\end{array}$ & $\begin{array}{c}\text { Can be done in the field or the } \\
\text { laboratory }\end{array}$ & $\begin{array}{c}\text { Structural and chemical } \\
\text { preservation are not } \\
\text { guaranteed } \\
\end{array}$ \\
\hline & Freeze-drying & $\begin{array}{l}\text { No use of chemicals or solvents, } \\
\text { ideal for drying ultrathin frozen } \\
\text { hydrated sections for room } \\
\text { temperature analysis }\end{array}$ & $\begin{array}{l}\text { Likelihood of movement of } \\
\text { target ions (particularly } \\
\text { diffusible elements) or } \\
\text { metabolites, especially in } \\
\text { highly vacuolated tissues }\end{array}$ \\
\hline & Freeze-substitution & $\begin{array}{c}\text { Dehydration at very low } \\
\text { temperature allows for good } \\
\text { structural and chemical } \\
\text { preservation }\end{array}$ & $\begin{array}{l}\text { Use of solvents can extract } \\
\text { materials of interest; long } \\
\text { process (days - weeks) }\end{array}$ \\
\hline \multirow{2}{*}{$\begin{array}{l}\text { Use of chemical } \\
\text { fixative during the } \\
\text { freeze substitution }\end{array}$} & Osmium & $\begin{array}{l}\text { Membranes are fixed, and } \\
\text { osmium provides contrast for EM } \\
\text { investigation and structural } \\
\text { information in XRF }\end{array}$ & $\begin{array}{l}\text { Highly toxic, Interfere with } \\
\text { some molecules and } \\
\text { elements for XRF and ToF- } \\
\text { SIMS analysis. }\end{array}$ \\
\hline & Aldehydes & $\begin{array}{l}\text { Proteins are fixed, maintaining } \\
\text { structural preservation }\end{array}$ & $\begin{array}{l}\text { Toxic, no contrast for EM } \\
\text { investigation, cannot be } \\
\text { prepared as anhydrous } \\
\text { (therefore loss of any water- } \\
\text { soluble material). }\end{array}$ \\
\hline
\end{tabular}




\begin{tabular}{|c|c|c|c|}
\hline & Acrolein & $\begin{array}{l}\text { Cross links at low temperatures } \\
\text { making it highly suited for use } \\
\text { with freeze substitution, can be } \\
\text { anhydrous }\end{array}$ & Hazardous material \\
\hline \multirow[b]{2}{*}{ Resin Embedding } & Plastic-Epoxy resin & $\begin{array}{c}\text { Good structural preservation and } \\
\text { contrast }\end{array}$ & $\begin{array}{c}\text { Often contain } \mathrm{Cl} \text {; require } \\
\text { solvents for good infiltration }\end{array}$ \\
\hline & Methacrylate resins & $\begin{array}{l}\text { Preservation of antigenicity; low } \\
\text { viscosity ideal for difficult-to- } \\
\text { embed samples }\end{array}$ & $\begin{array}{c}\text { Poor stability under an ion } \\
\text { beam; usually require O-free } \\
\text { environment to cure }\end{array}$ \\
\hline \multirow[b]{2}{*}{ Sectioning } & Wet sectioning & Easy to collect the sections & $\begin{array}{c}\text { Highly diffusible molecules } \\
\text { can be washed out }\end{array}$ \\
\hline & Dry sectioning & $\begin{array}{l}\text { Avoidance of water/liquids } \\
\text { allowing retainment of water } \\
\text { soluble ions and molecules }\end{array}$ & $\begin{array}{c}\text { Difficult to cut sections } \\
\text { thinner than } 500 \mathrm{~nm} ; \\
\text { difficult to obtain flat / } \\
\text { uncompressed sections for } \\
\text { analysis }\end{array}$ \\
\hline Cryo-analysis & Frozen hydrated cells & $\begin{array}{l}\text { The best structural and chemical } \\
\text { preservation close to the native } \\
\text { state, whole cells or cross } \\
\text { sections of cells can be analyzed }\end{array}$ & $\begin{array}{c}\text { Lack of contrast and } \\
\text { structural information; } \\
\text { correlative approaches across } \\
\text { platforms currently difficult; } \\
\text { cryo-sectioning (microtomy } \\
\text { or cryo-FIB) highly } \\
\text { specialized }\end{array}$ \\
\hline
\end{tabular}

Table 1. Detailed procedures of the sample preparation for EM and chemical imaging, and considerations (Pros and cons) for each step.

\section{Correlated subcellular imaging towards integrative cell biology}

154 Correlation between morphology and chemical imaging. Since chemical imaging provides

155 little morphological information, combination with light/electron microscopy is required in order

156 to unambiguously elucidate the localization of elements and molecules within a cell. Yet, the

157 challenge is the trade-off between ultrastructure and chemistry preservation of the cell during the

158 sample preparation, and the ability to transfer and analyze the same cells on different imaging

159 platforms. Some imaging techniques, such as SIMS, are destructive, meaning that morphological

160 imaging must generally take place before. Here we propose different strategies that can be adopted

161 to analyze the same cellular region of interest with multimodal imaging (Figure 1).

162 Organelles can be labeled and observed with fluorescence microscopy before the entire cell is

163 subjected to chemical imaging. For instance, the accumulation of $\mathrm{Mn}$ in the Golgi apparatus of

164 dopaminergic cells was revealed using green fluorescent proteins targeting the organelle followed

165 by S-XRF imaging in cryogenic conditions [53-55]. More recently, correlation between super-

166 resolution stimulated emission depletion microscopy of proteins and S-XRF imaging of trace

167 metals were performed with $40 \mathrm{~nm}$ spatial resolution on neurons [56].

168 To obtain high-resolution cellular context, it is also possible to analyze cell sections in S/TEM

169 followed by S-XRF, providing an unambiguous spatial origin of elements in subcellular 
compartments (Figures 3 and 4) [57]. Osmium tetroxide $\left(\mathrm{OsO}_{4}\right)$ can be used to fix and stain cellular compartments (Table 1), providing morphological contrast not only in EM, but also in S-XRF, where Os fluorescence reveals the ultrastructure of the cell (Figures 2 and 3; [12]. The drawback is that the XRF emission lines of Os interfere with those of phosphorous and some trace metals (e.g. $\mathrm{Cu}$ and $\mathrm{Zn}$ ), increasing their detection limit. In order to obtain structural and elemental/isotopic information from a single cellular region, it is possible to perform TEM followed by NanoSIMS (Figure 3). Usually it would require the use of a specific TEM grid with coordinates or fiducial markers to find the same regions of interest in both instruments (Figures 3 and 4) $[35,37,58,59]$. With the recent advent of sensitive backscatter detectors in the modern SEM it is also possible to acquire structural information from sections using SEM before nanoSIMS and S-XRF analyses, on the same sample or on consecutive sections $[12,41,60]$.

\section{Correlation between fluorescence and nanoSIMS using element labeling. The coupling} between fluorescence microscopy and nanoSIMS can be a powerful approach to unveil the functional identity of a cell and organelles. This relies on targeted probing of DNA, RNA and proteins by coupling fluorescent dyes to elements usually absent from cell's natural composition, such as halogens (fluorine, bromine), gold, and boron. A specific exogenous element (detectable by nanoSIMS) can be associated/linked to fluorescent dyes, antibodies, or nanobodies, allowing correlative microscopy between fluorescence in situ hybridization (FISH), immunocytochemistry or click chemistry approaches with nanoSIMS [23,61,62]. For example, the nucleotide analogue, bromo-deoxyurine (BrdU), which is incorporated into replicating DNA during cell division, can be detected by fluorescence immunohistochemistry but also as bromine ions (e.g., ${ }^{79} \mathrm{Br},{ }^{81} \mathrm{Br}$ ) by nanoSIMS in the same cells [63]. Fluorine $\left({ }^{19} \mathrm{~F}\right)$ labelling of proteins using ${ }^{19} \mathrm{~F}$-azide probe [64] or by conjugation to nanobodies (e.g. GFP-like proteins and antibodies) can enable correlated fluorescence and nanoSIMS imaging [65] (Figure 2). Similarly, ${ }^{197} \mathrm{Au}$ can be conjugated to an antibody to recognize cellular actin and synaptophysin proteins by coupled immunofluorescence and nanoSIMS [66], while antibodies tagged with isotopically-pure elemental metal reporters (i.e. lanthanides) have been utilized to image protein expression in human breast tumor tissue sections [67]. Recently, boron linked to proteins or to nanobodies binding to proteins have been used for simultaneous protein identification and elemental mapping by correlative fluorescence microscopy and nanoSIMS [68]. These studies suggest that exogenous elements with a small mass and size are 
suitable for probing DNA and proteins in the complex cellular environment and can be used in correlated nanoSIMS studies.

Correlation between more than two subcellular imaging platforms. The combination of multiple subcellular imaging platforms can provide a comprehensive view of the ultrastructure, concentration and distribution of elements (macronutrients and metals) and isotopic ratios, and molecules from a single region of interest in the cell (Figure 3). This can be performed by analyzing different consecutive resin sections from the same cell on different platforms $[12,13,57]$. This flexible strategy allows one to choose the required thickness and support (e.g. wafer, grid, Si window) for each section, and detailed ultrastructure can be obtained with EM. Thus, the morphological and different chemical features can be superimposed. Yet, collecting serial sections of different thicknesses to target the same cellular region or organelle is a challenge.

Integrated correlative instruments. A correlative approach can be facilitated when morphological and chemical information from exactly the same area can be acquired in the same instrument. One of the best examples is TEM-EDS and EFTEM. The TEM offers the highest possible resolution for both imaging and element analysis. Provided samples are thin (usually 150 $\mathrm{nm}-200 \mathrm{kV}$ ) and the elements of interest can be preserved, simultaneous structural and elemental information can be obtained at the nanoscale (Figure 3) [69]. However, molecular information is not available and absolute quantitation can be difficult. Using synchrotron X-rays nanoprobes, the combination between $\mathbf{X}$-ray phase contrast tomography and X-ray fluorescence microscopy can provide the morphological information and quantification of elements, respectively (Figure 3). This has been recently performed on a freeze-dried human phagocytic cell [16] and human red blood cells infected with the malaria parasite Plasmodium falciparum [70]. An alternative to phase contrast imaging is ptychography [71], which can be combined with XRF tomography to obtain the 3D localization of elements in cells, such as bacteria in [72].

New instruments that offer simultaneous morphological and molecular information are emerging but are yet to be applied to biological specimens. For instance, the HIM-SIMS (Secondary Ion Mass Spectrometry in the Helium-Ion Microscopy) can combine high-resolution morphological images with elemental and isotopic maps from SIMS [73]. In contrast to EDS on an SEM, HIMSIMS provides better detection limits for elements (including the very light ones) and 
differentiation between isotopes. However, using HIM-SIMS for stable-isotope labelling experiments will require a significant improvement of the mass resolution. Overall, the combination of high-resolution secondary electron images and mass-separated sputtered ion distributions has high potential to answer open questions in cell biology.

Image processing for multimodal correlative imaging. Upon acquisition on different imaging platforms, micrographs need to be processed to correlate or even overlap information from the same cellular region. Multimodal 2D microscopy requires registration algorithms that can analyze the same region but at different fields-of-views and resolutions from images acquired with different excitation probes (e.g. photons, electrons and ions) as well as different detectors. Compared to monomodal images processing, more sophisticated approaches are needed for multimodal images since the pixel-intensity of features is not comparable or do not even occur in both images. The additional challenge in multimodal data sets is the shape of the object that might be different because of preparation steps or different probing depths of the microscopes. Distortions may also be introduced when subsequent sections, representing different depth layers of the sample, are used for correlative imaging. In this context, the ImageJ-based software Correlia has been recently developed for the registration of 2D-2D multi-modal microscopy data-sets (available on request).

\section{Perspectives and future challenges for multimodal subcellular imaging.}

\section{Subcellular mapping metabolites in cells.}

Visualization of the compartmentalized distribution of metabolites in cells is one of the most promising research avenues in biology. Recently, laser-based ionization mass spectrometry techniques have been successfully used in single-cell metabolomics profiling experiments, but the lateral resolution precludes imaging subcellular chemistry [74]. Mapping metabolites at subcellular level can be now envisioned with the revolutionary SIMS instrument Hybrid SIMS (3D OrbiSIMS, IONTOF) that combines the speed and high lateral resolution imaging capabilities of ToF-SIMS with unprecedented mass resolution (240K), mass accuracy (sub-ppm), dynamic range (S/N ratio $10^{5}$ ), and MS/MS capabilities of the Orbitrap Q-Exactive [75]. The instrument has been used to map the distribution of lipids and neurotransmitters in the hippocampal region 
of the mouse brain at the cellular and subcellular level. The 3D imaging capabilities were used to visualizing the accumulation of amiodarone in single lung macrophage cells, and assessing its toxic effect by correlating drug concentration with the levels of phospholipids and cholesterol [75].

\section{Future improvements needed to probe cells in their native state and in four dimensions. The} future of chemical imaging largely relies in the development of cryo-analyses and associated correlative workflows to allow multiscale chemical analysis of cells in their native state across multiple instruments. Currently, cryo-analyses present limitations in regard to the suitability of samples for cryo-preservation and their transfer between different platforms without ice contamination. In most cases, frozen cells must be sectioned/milled in order to visualize the interior. Future expansion in this area will require improvements in preparation of quality cryosections (e.g. cryo-FIB-SEM), development of cryo-enabled instrument platforms (e.g. nanoSIMS), and the capability to transfer samples seamlessly between these. Additional challenges associated to cryo-imaging are the low contrast of vitrified cells and possible devitrification under irradiation from the probe (e.g. ions, X-rays).

Chemical information in $2 \mathrm{D}$ is insufficient to fully describe the compartmentalization of an element/molecule throughout an entire cell, especially when information comes from a single thin section (60-300 $\mathrm{nm}$ thickness) of a cell. Techniques to acquire 3D structural information at the subcellular level are readily available (e.g. FIB-SEM) but it is difficult to couple these with analytical information. Synchrotron-based coherent X-ray scattering techniques such as holotomography or ptychography have both demonstrated constant improvements toward ultrastructural 3D characterization of a cell architecture [76]. We therefore foresee a bright future in the coupling between these techniques with X-ray fluorescence tomography for 3D elemental imaging.

The down side of high-resolution chemical imaging is the low throughput, which precludes for robust statistical analyses. We can expect that ultra-high-speed scanning strategy and highly efficient detection will be the next steps to foster on the instrumentation side. For example, extremely brilliant X-ray synchrotron source and high-rate scanning strategies become reality with the upgrade of the synchrotrons, such as the European Synchrotron Radiation Facility (ESRF) [77]. 
Finally, future developments need to integrate a biologically-relevant temporal dimension into the correlative imaging workflow towards 4D imaging. Because probing elements and molecules of live cells at the nanoscale level remain very challenging, there is a need to capture multiple snapshots of a phenotypic state of a cell over time to follow and better understand dynamic cellular processes following exposure to abiotic or biotic stress. One single snapshot may provide a biased vision of the phenotypic response of a cell if imaging analysis occurs on the inappropriate timescale. Temporal resolution can be obtained by the coupling with live imaging (fluorescent and super resolution microscopy) and developing microfluidic devices [78], or rapid cryo-fixation strategies [79]. For instance, dynamic fluorescent light microscopy can be rapidly followed by cryo-immobilization in few seconds for CLEM studies thanks to new tools (e.g. CryoCapsule), and could be extended to chemical imaging in the future [80]. In addition, recent advances in superresolution fluorescence microscopy (e.g. Stimulated emission depletion - STED - microscopy) [81] and future development of new fluorescent element-specific probes will potentially provide a dynamic view of labile elements (e.g. $\mathrm{Ca}^{2+}, \mathrm{Fe}^{2+/ 3+}, \mathrm{Zn}^{2+}$ ) in live cells at $10-50 \mathrm{~nm}$ resolution [82]. Correlation with chemical imaging will open new perspectives for bridging temporal and spatial resolution [83].

Thus, the development of time-resolved 3D subcellular imaging in cryo-conditions will be a major breakthrough in cell biology to capture dynamic subcellular processes in a native-state cell.

\section{Outstanding Questions}

- Is it possible to preserve the native physiological state of a cell from sample preparation to subcellular imaging? How can structural and chemical preservation of the cell be carefully assessed and artefacts identified to avoid misleading results?

- Can we resolve the chemical landscape (composition and distribution of elements and molecules) of a cell with high spatial resolution, in three dimensions and over a relevant temporal scale? What would be the analytical workflow to implement for 4D subcellular imaging?

- What are the methodological and technological strategies to analyze the same subcellular region of interest across different subcellular imaging techniques?

- How can we include cryo-analysis in the workflow of correlative subcellular imaging, from sample preparation to obtain vitreous cells, to transfer and imaging across different platforms? Can it be applied to different types of cells from a tissue or isolated in culture or the environment? 
- How can the throughput of chemical imaging techniques be increased to observe large numbers of biological samples and perform robust statistical comparisons?

- Can we enhance the mass and spatial resolution of SIMS imaging instruments in order to visualize a large number of different metabolites in the cell?

\section{Concluding Remarks}

314 Subcellular chemical imaging techniques are constantly improving and becoming ever-more powerful tools for quantitative visualization of elements, isotopes, and molecules in cells. However, untangling their complex requirements and capabilities is a vital step in ensuring that researchers can apply such methods to outstanding research questions and problems. With this, appropriate sample preparation and suitable imaging platform(s) need to be selected according to the sample, spatial resolution, and targeted elements/molecules. In this review, we have outlined the principles of key analytical instrumentation, discussed strategies for sample preparation, and highlighted the potential for correlative electron microscopy and chemical imaging to accumulate structural and chemical information from a single region of a cell. Correlated morphological and chemical imaging has the potential to spur a rapid expansion in different fields, such as cell biology, biomedicine, ecophysiology, pharmacology, toxicology, biogeochemistry. In the near future, we do not foresee a technique that would encompass all the capabilities to explore the chemical/molecular/isotopic composition and ultrastructure of a cell. Thus, the development of integrative studies and dedicated analytical correlative workflows, from sample preparation to multimodal imaging and image processing, will be a major contribution towards a full comprehension of the physiology of a cell at the subcellular level.

\section{Glossary}

- Chemical imaging: spatial characterization of the chemical composition of a sample (isotopes, elements, molecules). This can be achieved by multiple high-resolution imaging platforms, using different physical processes to interrogate subcellular information (e.g. X-ray fluorescence, ionization) 
- Chemical landscape: Composition and distribution patterns of elements, isotopes and molecules in a sample (e.g. cell). Its visualization cannot be obtained with a single imaging platform but different techniques need to be used in a correlative way.

- Correlative electron microscopy and chemical imaging: workflow to prepare samples, obtain micrographs from different complementary imaging platforms, and overlap morphological and chemical (elements/molecules) information from the same region of a specimen.

- HybridSIMS: [Bi]n (n=1, 3, 5, 7) or [Ar]n (n 1000) gas-cluster ion source are used for analysis of large molecular ions. The OrbiTrap analyzer provide a MRP of $\sim 10 \mathrm{E} 5$ that enables a precise compound identification.

- Multimodal imaging: Microscopy observations of the same sample using more than two imaging platforms to obtain complementary morphological and chemical information (e.g. light and electron microscopy, nanoSIMS and S-XRF).

-nanoSIMS: single-atomic Cs+ or O- primary ions are used for both sputtering and analysis, the ionized material is then analyzed by a Mattauch-Herzog mass spectrometer that allows for the parallel detection of max 7 masses. The high energy of the primary ions causes a strong fragmentation of molecules down to single-atomic ions allowing for quantitation of changes in isotopic composition.

- SIMS: secondary ion mass spectrometry whereby secondary ions are sputtered away from the topmost layer of a sample by a focused primary ion beam and analyzed in a mass spectrometer. NanoSIMS, ToF-SIMS and HybridSIMS are SIMS imaging techniques with primary ion beams of different sources and energies, and with different mass spectrometers to probe elements, isotopes and small molecules.

- ToF-SIMS: pulsed [Bi]n ( $\mathrm{n}=1,3,5,7)$ or [Ar]n (n 1000) cluster ion sources are mainly used for analysis while Ar [n] cluster, Cs+ or O- can be used as sputtering sources. The use of cluster ions for analysis reduces the fragmentation upon impact, leading to the preservation of molecular species. The Time-of-Flight mass spectrometer allows the simultaneous detection of all masses.

- Vitreous cell: Frozen hydrated cell with amorphous ice (i.e. without crystals that can alter the ultrastructure and chemical composition of cells). Vitreous cell can be obtained using highpressure freezing or plunge freezing machines. 
- X-ray fluorescence microscopy (XRF): physical process consisting on the emission of Xrays from a specimen following the excitation of core electrons of atoms; the analysis of the emitted X-rays allows the identification of the elemental content of the specimen. The excitation of electrons can be achieved by a beam of electrons, protons or photons.

- X-ray phase contrast tomography: Tomographic technique sensitive to refraction of Xrays in matter, leading to phase variations of the X-rays depending on the sample's electron density, and particularly adapted to reveal weakly absorbing features like those present in biological samples. 


\section{$333 \quad$ Figure}

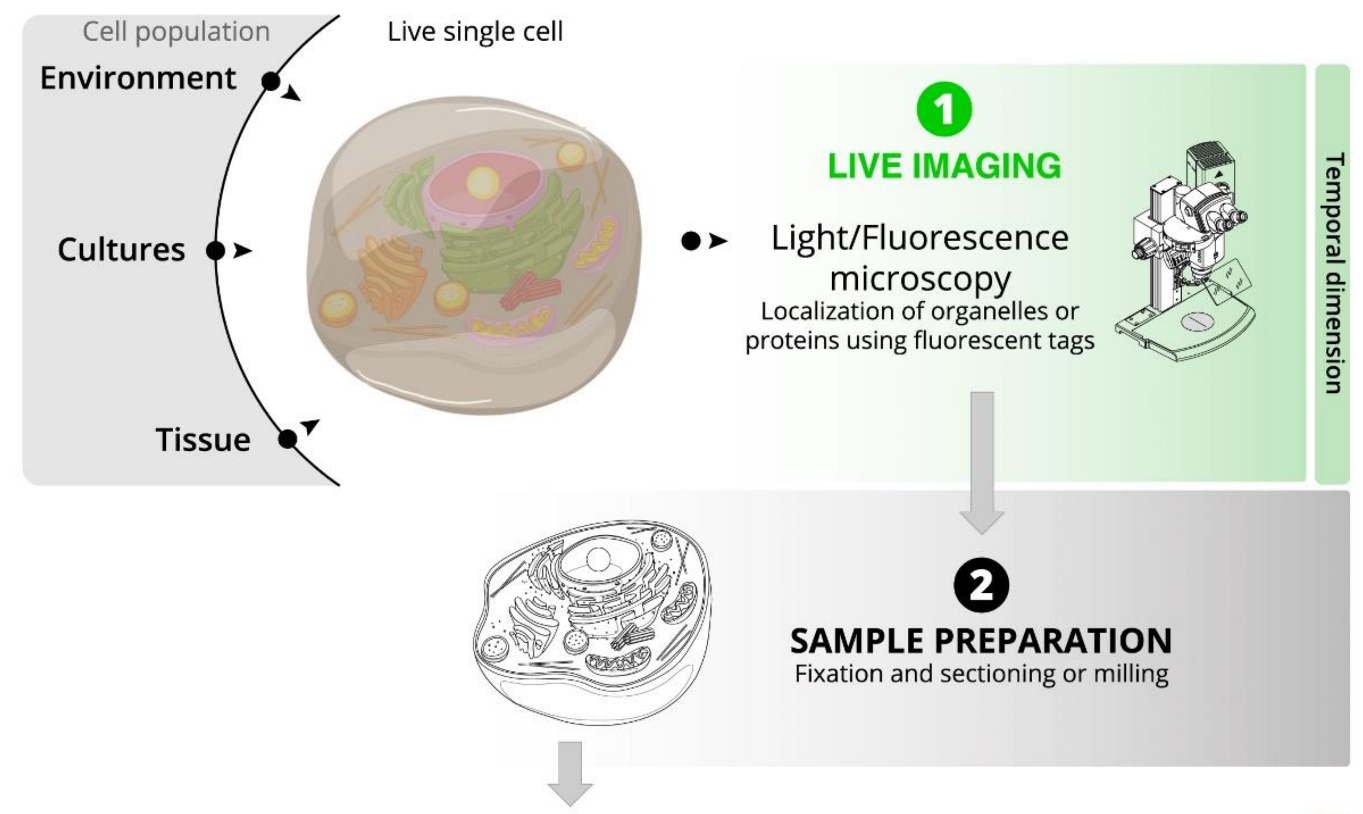

\section{SUBCELLULAR IMAGING}
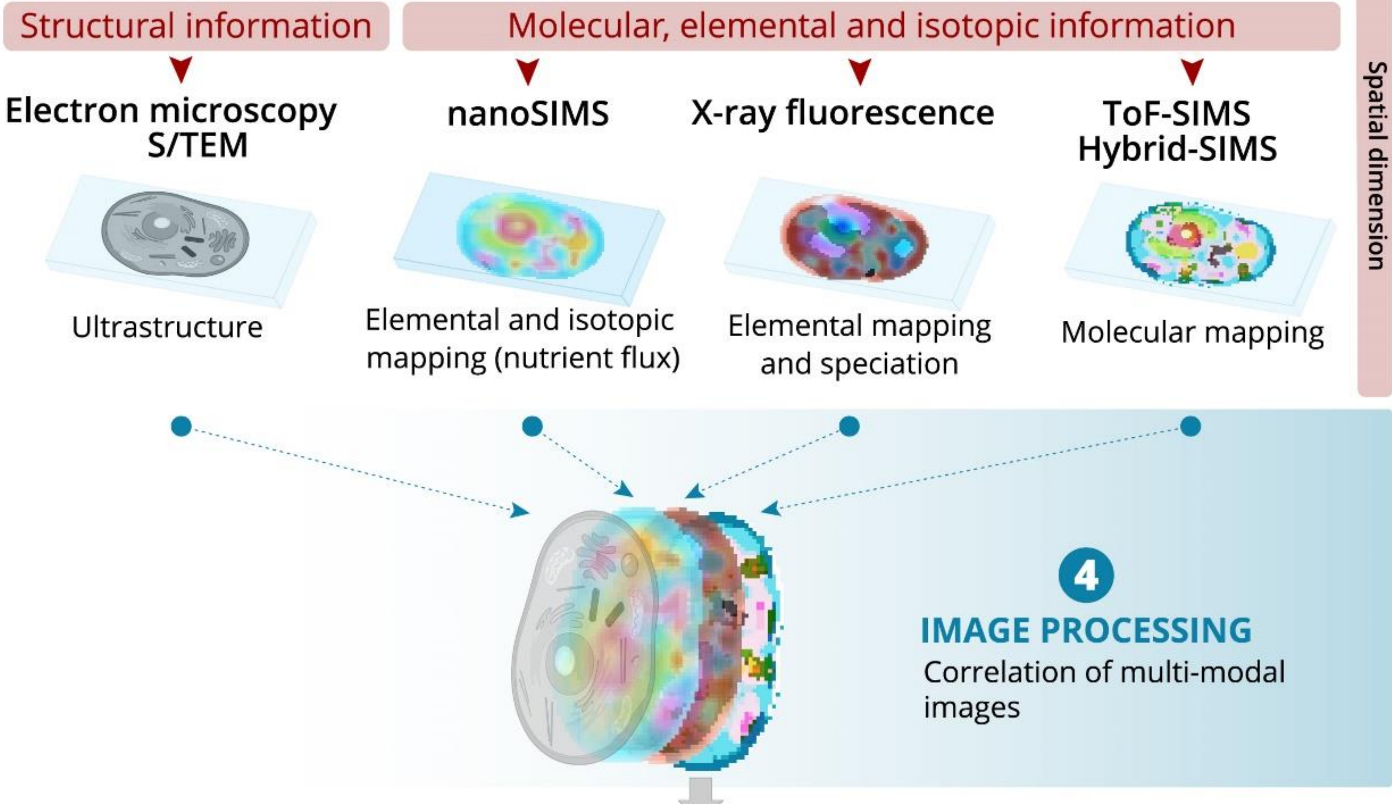

\section{VISUALIZATION AND QUANTIFICATION OF SUBCELLULAR PROCESSES}

Homeostasis of elements (e.g. metals)

Nutrient flux (uptake and allocation) in the cell

Fate of exogenous elements (drug, heavy metal, nanoparticle) in the cell

Localization of molecules, such as lipids in the cell 


\section{Figure 1 - Key figure. Outline of correlative multimodal subcellular imaging workflow}

336 including electron and chemical imaging. Individual cells can be isolated from a population in

337 a tissue, culture or in the environment, and observed in vivo using light/fluorescence microscopy

338 for dynamic and functional imaging. After sample preparation (fixation and sectioning/milling), a

339 cell can be analyzed by different high-resolution imaging platforms in a correlative way. Electron

340 microscopy can unveil detailed ultrastructure of the cell while chemical imaging platforms

341 (nanoSIMS, X-ray fluorescence, ToF-SIMS, Hybrid-SIMS) enable the visualization and

342 quantification of elements, isotopes and molecules at the subcellular level. Finally, image

343 processing allows the correlation between multimodal micrographs that contain complementary

344 information of the cell. This workflow still requires some methodological developments at

345 different steps, from sample preparation to image processing, in order to further understand the

346 metabolism and physiology of a cell at the nanoscale in its close-to-native state. 


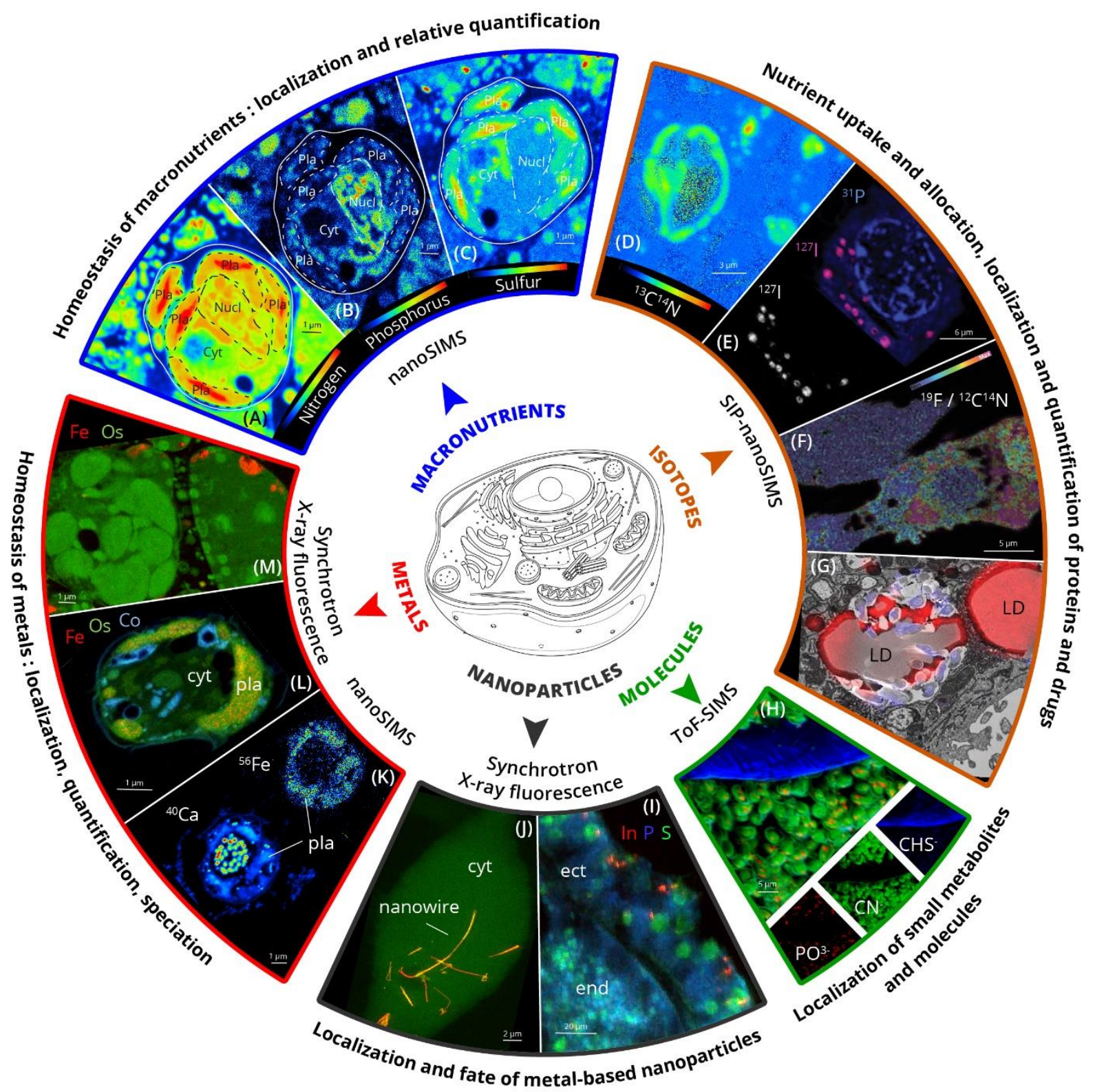

348 Figure 2. The potential of chemical imaging to unveil the chemical landscape of a cell: 349 composition and distribution of elements, isotopes and molecules at the nanoscale.

350 (A-B-C) NanoSIMS images showing the distribution of the macronutrients nitrogen $\left(\mathrm{A} ;{ }^{12} \mathrm{C}^{14} \mathrm{~N}^{-}\right)$, 351 phosphorous $\left(\mathrm{B} ;{ }^{31} \mathrm{P}^{-}\right)$, and sulfur $\left(\mathrm{C} ;{ }^{32} \mathrm{~S}^{-}\right)$inside a microalgal cell.

352 (D) NanoSIMS image showing the uptake of ${ }^{13} \mathrm{C}$ incorporated in proteins $\left({ }^{13} \mathrm{C}^{14} \mathrm{~N}\right)$ in cells after 353 incubation in ${ }^{13} \mathrm{C}$-labelled bicarbonate (SIP-nanoSIMS).

354 (E) NanoSIMS image acquired on macrophages treated with the drug Iodine-containing 355 amiodarone. The overlay of ${ }^{31} \mathrm{P}^{-}$(blue) and ${ }^{127} \mathrm{I}^{-}$(purple) secondary ions map provides 
morphological information (localization of the nucleus) and shows specific localization of the drug within the lysosomes. Reproduced with permission from [84].

(F) Specific labeling of proteins for correlated fluorescence microscopy and nanoSIMS using FluorLink-nanobody anti-GFP and direct immunostaining strategies. NanoSIMS image of ${ }^{19} \mathrm{~F} /{ }^{12} \mathrm{C}^{14} \mathrm{~N}$ ratio shows the presence of the targeted protein in specific cellular areas. Reproduced with permission from [65].

(G) Visualization of antibiotic in cells. Overlay of nanoSIMS and electron microscopy images showing the accumulation of the antibiotic in lipid droplets (LD). The bromine-containing antibiotic (bedaquiline) can be detected and semi-quantified by the nanoSIMS through the ${ }^{79} \mathrm{Br}$ ions (red signal). Reproduced with permission from [41].

(H) ToF-SIMS images showing accumulation of phosphates (red, $\mathrm{PO}^{3-}$ ) in biofilm of algal cells (green, $\mathrm{CN}^{-}$) growing in cotton (blue, $\mathrm{CH}_{4} \mathrm{~S}^{-}$). Reproduced with permission from [47].

(I) Synchrotron X-ray Fluorescence image showing the distribution of indium phosphide-based nanocrystals in a frozen section of the Hydra vulgaris. Nanocrystals (detected by indium X-ray fluorescence, in red) are mainly internalized in the ectoderm layer (ect). The natural macronutrients phosphorous (blue) and sulfur (green) provide the morphological context. Reproduced with permission from [21].

(J) Synchrotron X-ray Fluorescence image showing the presence of silver nanowires in a fibroblast cell ( $\mathrm{S}$ in green, and $\mathrm{Ag}$ in red). Yellow regions indicate colocalization of $\mathrm{Ag}$ and $\mathrm{S}$ inside the cell. Reproduced with permission from [4]. Copyright 2019 National Academy of Sciences.

(K) NanoSIMS image showing the distribution of $\mathrm{Ca}\left({ }^{40} \mathrm{Ca}^{+}\right)$and $\mathrm{Fe}\left({ }^{56} \mathrm{Fe}^{+}\right)$in a microalga. Calcium mapping unveils the overall morphology of the cells with high concentration in the nucleus (nucl). Iron is mostly contained in the plastids (pla).

(L-M) Synchrotron X-Ray Fluorescence images showing the subcellular distribution and quantification of the trace metals Fe (red) and Co (blue), and Os (green) in microalgal cells.

Abbreviations: Pla: plastid of microalgal cell; Cyt: cytoplasm; Nucl: nucleus; LD: Lipid droplet; ect: ectoderm; end: endoderm. 

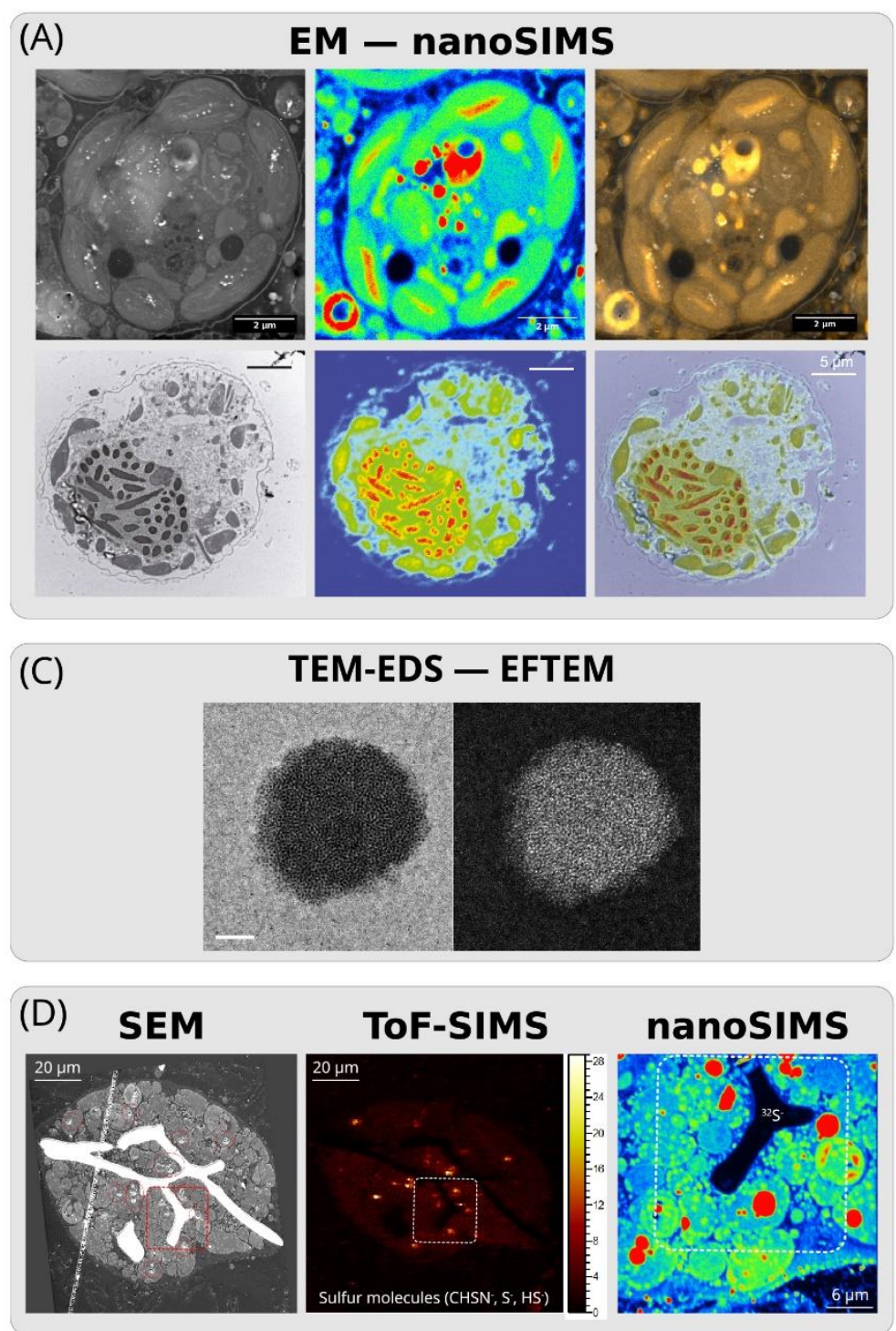

\section{(F) X-ray phase contrast tomography $X$-ray fluorescence tomography}

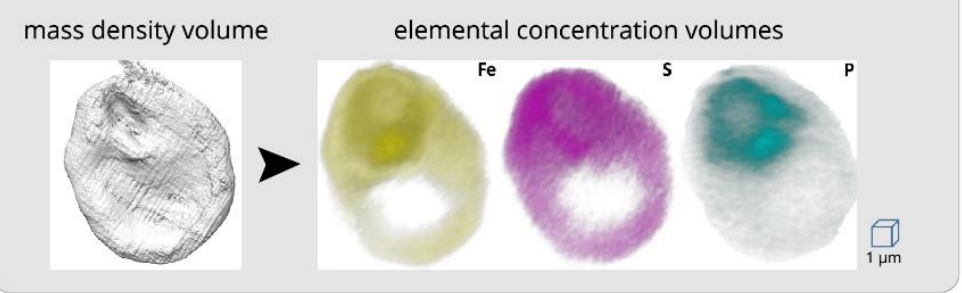

(B) SEM - SXRF
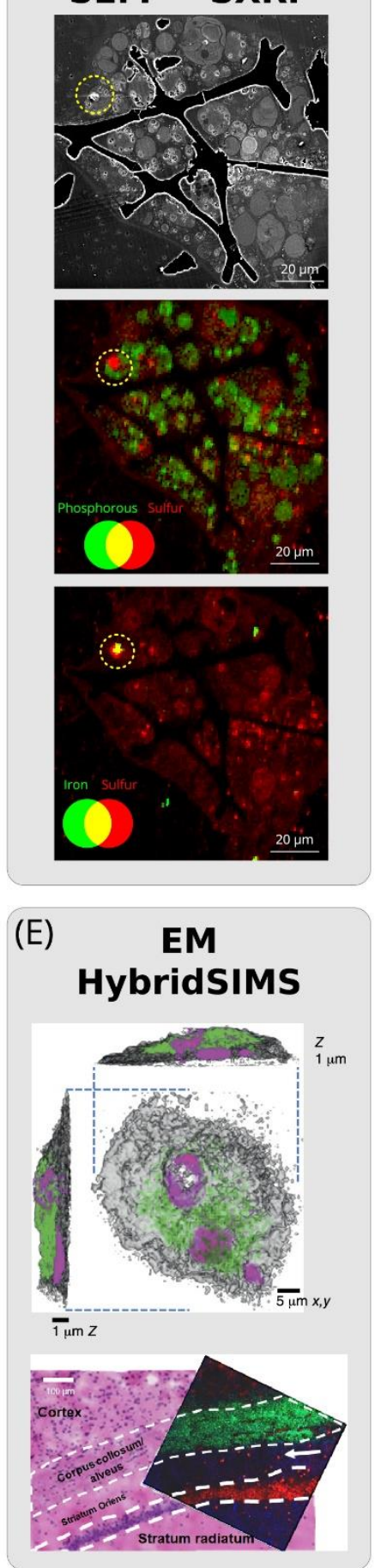

386 Figure 3. Examples of correlated electron microscopy and chemical imaging. 
(A) Correlation between electron microscopy (left images) and nanoSIMS (middle images) showing the sulfur $\left({ }^{32} \mathrm{~S}^{-}\right.$, upper image) and nitrogen $\left({ }^{12} \mathrm{C}^{14} \mathrm{~N}^{-}\right.$, lower image) content in a microalgal cell. Right images show the overlay of macronutrient mapping and ultrastructure obtained from consecutive sections or the same section. Image courtesy of Charlotte Lekieffre.

(B) Correlation between scanning electron microscopy (SEM) and Synchrotron X-Ray Fluorescence microscopy (S-XRF). SEM observation has been performed on the same cell section after S-XRF analysis. S-XRF mapping of phosphorous and iron (green), and sulfur (red) unveils numerous hotspots (one example highlighted by the yellow circle) where sulfur and iron are colocalized in high concentration in the cell.

(C) TEM image (left) with corresponding EFTEM (Energy-Filtered Transmission Electron Microscopy Fe map (right) showing aggregated ferritin molecules within a cell (courtesy Jeremy Shaw and David Keays). Scale bar $=100 \mathrm{~nm}$.

(D) Correlation between Scanning Electron Microscopy, ToF-SIMS and nanoSIMS showing the cell ultrastructure, distribution of sulfur molecules $\left(\mathrm{CHSN}^{-}, \mathrm{S}^{-}, \mathrm{HS}^{-}\right)$and sulfur $\left({ }^{32} \mathrm{~S}^{-}\right)$, respectively. These multimodal images were acquired from consecutive thin sections.

(E) EM- Hybrid SIMS image showing the 3D distribution in a single cell of the drug amiodarone (m/z 646, green) and biomolecules at m/z 157 (purple) and m/z 184 (green) (upper image). Lower image obtained from the hybrid SIMS instrument shows that C24:1 sulfatides ( $\mathrm{m} / \mathrm{z} 888.62$, green) are localized to the corpus collosum. DNA base adenine (red, m/z 134.05), a nuclear marker, shows that neurons are densely packed in the pyramidal layer and sparsely packed in the Stratum Oriens, where phosphoinositol is located ( $\mathrm{m} / \mathrm{z}$ 241.01, blue). Figure adapted with permission from [75].

(F) Direct correlation between X-ray phase contrast and X-ray fluorescence tomography on a malaria-infected cell. The 3D mass density volume is obtained as after tomographic reconstruction (on the left). Subsequent X-ray fluorescence scanning measurements were performed on the same sample showing the 3D mass concentration volumes of iron, sulfur, and phosphorous (on the right). Reproduced with permission from [70]. 


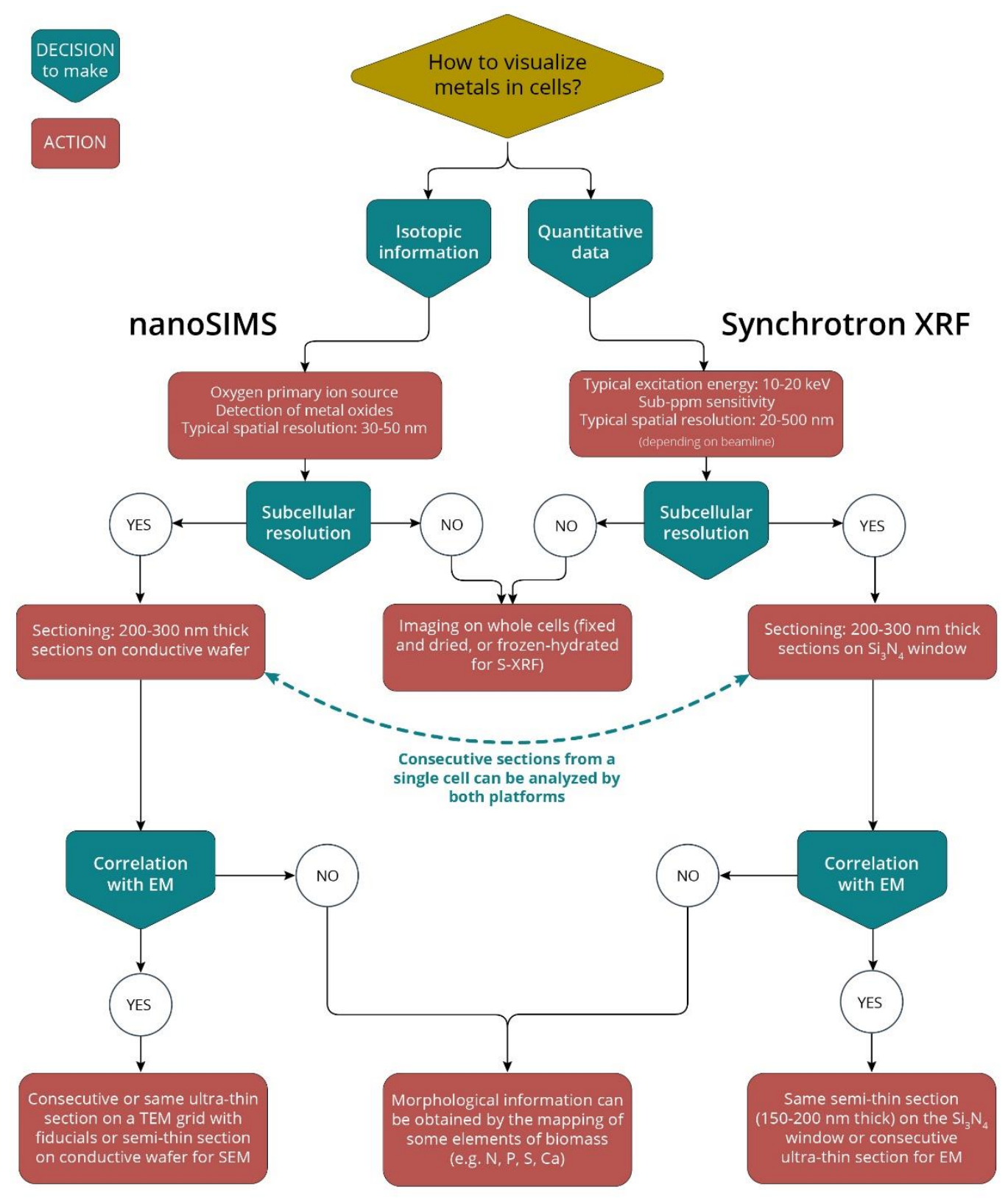

415

416 Figure 4. How to visualize metals in cells?

417 Decision flowchart to guide users for probing metals in a single cell at high resolution and 418 sensitivity.. 


\section{Acknowledgements}

420

421

422

423

424

425

426

427

428

429

430

431

$432 \quad 1$

433

434

435

436

437

4384

J.D was supported by the LabEx GRAL (ANR-10-LABX-49-01), Pôle CBS from the University of Grenoble Alpes, and Défi X-Life grant from CNRS. The authors acknowledge the support and use of resources from Instruct (a Landmark ESFRI project) and the ESRF for providing beamtime. We are thankful for the use of the analytical facilities of the Centre for Chemical Microscopy (ProVIS) at UFZ Leipzig, which is supported by European Regional Development Funds (EFREEurope funds Saxony) and the Helmholtz Association. This research is also supported by EMBRCFrance, whose French state funds are managed by the ANR within the Investments of the Future program under reference ANR-10-INBS-02. We also thank Yannick Schwab for critically reading the manuscript and suggesting improvements. We are grateful to colleagues for sharing microscopy images.

\section{References}

1 Salt, D.E. et al. (2008) Ionomics and the study of the plant ionome. Annual review of plant biology 59, 709-733

2 Hackett, M.J. et al. (2019) Elemental characterisation of the pyramidal neuron layer within the rat and mouse hippocampus. Metallomics 11, 151-165

3 Veronesi, G. et al. (2016) Visualization, quantification and coordination of $\mathrm{Ag}^{+}$ions released from silver nanoparticles in hepatocytes. Nanoscale 8, 17012-17021

4 Lehmann, S.G. et al. (2019) Crumpling of silver nanowires by endolysosomes strongly reduces toxicity. Proceedings of the National Academy of Sciences 116, 14893-14898

5 de Boer, P. et al. (2015) Correlated light and electron microscopy: ultrastructure lights up! Nature Methods 12, 503-513

6 Karreman, M.A. et al. (2016) Intravital Correlative Microscopy: Imaging Life at the Nanoscale. Trends in Cell Biology 26, 848-863

da Cunha, M.M.L. et al. (2016) Overview of chemical imaging methods to address biological questions. Micron 84, 23-36

8 Baker, T.C. et al. (2017) Recent advancements in matrix-assisted laser desorption/ionization mass spectrometry imaging. Current Opinion in Biotechnology 43, 62-69

9 Lauwers, M. et al. (2013) An iron-rich organelle in the cuticular plate of avian hair cells. Current Biology 23, 924-929

0 Cotte, M. et al. (2017) The ID21 X-ray and infrared microscopy beamline at the ESRF: status and recent applications to artistic materials. J. Anal. At. Spectrom. 32, 477-493 
$452 \quad 11$

453

454

455

456

457

$458 \quad 14$

459

460

461

462

463

464

465

466

$467 \quad 17$

468

471

472

473

474

475

476

477

$478 \quad 21$

479

480

481

482

483

484

485

486

487

488

489

490

Pushie, M.J. et al. Elemental and chemically specific x-ray fluorescence imaging of biological systems. , Chemical Reviews, 114. (2014) , 8499-8541

12 Decelle, J. et al. (2019) Algal Remodeling in a Ubiquitous Planktonic Photosymbiosis. Current Biology DOI: 10.1016/j.cub.2019.01.073

13 Kashiv, Y. et al. (2016) Imaging trace element distributions in single organelles and subcellular features. Scientific Reports 6, 21437

4 Adams, M.S. et al. (2016) Copper Uptake, Intracellular Localization, and Speciation in Marine Microalgae Measured by Synchrotron Radiation X - ray Fluorescence and Absorption Microspectroscopy. DOI: 10.1021/acs.est.6b00861

15 Ciccotosto, G.D. et al. (2014) Quantitation and localization of intracellular redox active metals by X-ray fluorescence microscopy in cortical neurons derived from APP and APLP2 knockout tissue. Metallomics 6, 1894-1904

16 Gramaccioni, C. et al. (2018) Nanoscale quantification of intracellular element concentration by $\mathrm{X}$-ray fluorescence microscopy combined with X-ray phase contrast nanotomography. Applied Physics Letters 112,

7 Brown, K. et al. (2018) Intracellular in situ labeling of $\mathrm{TiO} 2$ nanoparticles for fluorescence microscopy detection. Nano Research 11, 464-476

18 Fus, F. et al. (2019) Intracellular Localization of an Osmocenyl-Tamoxifen Derivative in Breast Cancer Cells Revealed by Synchrotron Radiation X-ray Fluorescence Nanoimaging. Angewandte Chemie International Edition 58, 3461-3465

19 Kapishnikov, S. et al. (2019) Mode of action of quinoline antimalarial drugs in red blood cells infected by Plasmodium falciparum revealed in vivo. Proceedings of the National Academy of Sciences DOI: 10.1073/pnas.1910123116

20 Sanchez-Cano, C. et al. (2019) Nanofocused synchrotron X-ray absorption studies of the intracellular redox state of an organometallic complex in cancer cells. Chemical Communications $55,7065-7068$

21 Veronesi, G. et al. (2019) In Vivo Biotransformations of Indium Phosphide Quantum Dots Revealed by X-Ray Microspectroscopy. ACS Applied Materials \& Interfaces 11, 35630-35640

22 Hackett, M.J. et al. (2016) Chemical biology in the embryo: In situ imaging of sulfur biochemistry in normal and proteoglycan-deficient cartilage matrix. Biochemistry 55, 2441-2451

23 Gyngard, F. and Steinhauser, M.L. (2019) Biological explorations with nanoscale secondary ion mass spectrometry. Journal of Analytical Atomic Spectrometry 34, 1534-1545

24 Agüi-Gonzalez, P. et al. (2019) SIMS imaging in neurobiology and cell biology. Journal of Analytical Atomic Spectrometry 34, 1355-1368

25 Malherbe, J. et al. (2016) A new RF plasma oxygen primary ion source on NanoSIMS for improved lateral resolution and detection of electropositive elements at single cell level. Analytical Chemistry DOI: 10.1021/acs.analchem.6b01153

26 Nuñez, J. et al. (2018) NanoSIMS for biological applications: Current practices and analyses. Biointerphases 13, 03B301 
Weng, N. et al. (2017) In situ subcellular imaging of copper and zinc in contaminated oysters revealed by nanoscale secondary ion mass spectrometry. Environmental Science \& Technology DOI: $10.1021 /$ acs.est.7b05090

28 Tsednee, M. et al. (2019) Manganese co-localizes with calcium and phosphorus in Chlamydomonas acidocalcisomes and is mobilized in Mn-deficient conditions. Journal of Biological Chemistry DOI: 10.1074/jbc.RA119.009130

29 Mayali, X. (2020) NanoSIMS: Microscale Quantification of Biogeochemical Activity with LargeScale Impacts. Annual Review of Marine Science 12, 1-19

30 Musat, N. et al. (2016) Tracking microbial interactions with NanoSIMS. Current Opinion in Biotechnology 41, 114-121

31 Stryhanyuk, H. et al. (2018) Calculation of single cell assimilation rates from sip-nanosimsderived isotope ratios: A comprehensive approach. Frontiers in Microbiology 9, 1-15

32 Berthelot, H. et al. (2018) NanoSIMS single cell analyses reveal the contrasting nitrogen sources for small phytoplankton. The ISME Journal DOI: 10.1038/s41396-018-0285-8

33 Terrado, R. et al. (2017) Autotrophic and heterotrophic acquisition of carbon and nitrogen by a mixotrophic chrysophyte established through stable isotope analysis. ISME Journal 11, 20222034

34 He, C. et al. (2018) NanoSIMS imaging reveals unexpected heterogeneity in nutrient uptake by brown adipocytes. Biochemical and Biophysical Research Communications 504, 899-902

35 Lekieffre, C. et al. (2018) Inorganic carbon and nitrogen assimilation in cellular compartments of a benthic kleptoplastic foraminifer. Scientific Reports 8, 1-12

Volland, J.M. et al. (2018) NanoSIMS and tissue autoradiography reveal symbiont carbon fixation and organic carbon transfer to giant ciliate host. ISME Journal 12, 714-727

37 Gibbin, E. et al. (2019) Vibrio coralliilyticus infection triggers a behavioural response and perturbs nutritional exchange and tissue integrity in a symbiotic coral. ISME Journal 13, 989-1003

38 Martínez-Pérez, C. et al. (2016) The small unicellular diazotrophic symbiont, UCYN-A, is a key player in the marine nitrogen cycle. Nature Microbiology 1, 16163

39 Pasulka, A.L. et al. (2018) Interrogating marine virus-host interactions and elemental transfer with BONCAT and nanoSIMS-based methods. Environmental Microbiology 20, 671-692

40 Worrich, A. et al. (2017) Mycelium-mediated transfer of water and nutrients stimulates bacterial activity in dry and oligotrophic environments. Nature Communications 8 ,

41 Greenwood, D.J. et al. (2019) Subcellular antibiotic visualization reveals a dynamic drug reservoir in infected macrophages. Science (New York, N.Y.) 364, 1279-1282

42 Vanbellingen, Q.P. et al. (2015) Time-of-flight secondary ion mass spectrometry imaging of biological samples with delayed extraction for high mass and high spatial resolutions. Rapid Communications in Mass Spectrometry 29, 1187-1195

43 Benettoni, P. et al. (2019) Identification of nanoparticles and their localization in algal biofilm by 3D-imaging secondary ion mass spectrometry. Journal of Analytical Atomic Spectrometry DOI: 
44 Henss, A. et al. (2018) High resolution imaging and 3D analysis of Ag nanoparticles in cells with ToF-SIMS and delayed extraction. Biointerphases 13, 03B410

45 Raina, J.-B. et al. (2017) Subcellular tracking reveals the location of dimethylsulfoniopropionate in microalgae and visualises its uptake by marine bacteria. eLife 6, 1-17

Dowlatshahi Pour, M. et al. (2019) Mass spectrometry imaging as a novel approach to measure hippocampal zinc. Journal of Analytical Atomic Spectrometry 34, 1581-1587

47 Osorio, J.H.M. et al. (2019) Investigation of architecture development and phosphate distribution in Chlorella biofilm by complementary microscopy techniques. FEMS Microbiology Ecology 95, $1-10$

48 Sämfors, S. et al. (2019) Localised lipid accumulation detected in infarcted mouse heart tissue using ToF-SIMS. International Journal of Mass Spectrometry 437, 77-86

49 Passarelli, M.K. et al. (2013) Single-cell lipidomics: Characterizing and imaging lipids on the surface of individual Aplysia californica neurons with cluster secondary ion mass spectrometry. Analytical Chemistry 85, 2231-2238

50 Moore, K.L. et al. (2014) Combined NanoSIMS and synchrotron X-ray fluorescence reveal distinct cellular and subcellular distribution patterns of trace elements in rice tissues. New Phytologist 201, 104-115

51 Zhou, J. et al. (2011) Reproducibility and quantitation of amplicon sequencing-based detection. The ISME Journal 5, 1303-1313

52 Perrin, L. et al. (2015) Evaluation of sample preparation methods for single cell quantitative elemental imaging using proton or synchrotron radiation focused beams. J. Anal. At. Spectrom. DOI: $10.1039 /$ C5JA00303B

53 Das, S. et al. (2019) Manganese Mapping Using a Fluorescent Mn 2+ Sensor and Nanosynchrotron X-ray Fluorescence Reveals the Role of the Golgi Apparatus as a Manganese Storage Site. Inorganic Chemistry 58, 13724-13732

54 Carmona, A. et al. (2019) Mapping Chemical Elements and Iron Oxidation States in the Substantia Nigra of 6-Hydroxydopamine Lesioned Rats Using Correlative Immunohistochemistry With Proton and Synchrotron Micro-Analysis. Frontiers in Neuroscience 13, 1-12

55 Carmona, A. et al. (2014) Environmental manganese compounds accumulate as Mn(ii) within the Golgi apparatus of dopamine cells: relationship between speciation, subcellular distribution, and cytotoxicity. Metallomics 6, 822

56 Domart, F. et al. (2019) Correlating STED and synchrotron XRF nano-imaging unveils the cosegregation of metals and cytoskeleton proteins in dendrites. Bioarchive DOI: http://dx.doi.org/10.1101/810754

57 Sanchez-Cano, C. et al. (2017) Synchrotron X-Ray Fluorescence Nanoprobe Reveals Target Sites for Organo-Osmium Complex in Human Ovarian Cancer Cells. Chemistry - A European Journal $23,2512-2516$

8 Clode, P.L. et al. (2009) In Situ Mapping of Nutrient Uptake in the Rhizosphere Using Nanoscale 
59 Kopp, C. et al. (2015) Subcellular Investigation of Photosynthesis-Driven Carbon Assimilation in the Symbiotic Reef Coral Pocillopora damicornis. mBio 6, 1-9

Hu, X. et al. (2019) Release of cholesterol-rich particles from the macrophage plasma membrane during movement of filopodia and lamellipodia. eLife 8, 1-26

Musat, N. et al. (2012) Detecting metabolic activities in single cells, with emphasis on nanoSIMS. FEMS microbiology reviews 36, 486-511

575

576

577

Saka, S.K. et al. (2014) Correlated optical and isotopic nanoscopy. Nature communications 5, 3664

63 Lau, K.H. et al. (2010) Development of a new bimodal imaging methodology: a combination of fluorescence microscopy and high-resolution secondary ion mass spectrometry. Journal of microscopy 240, 21-31

64 Vreja, I.C. et al. (2015) Secondary-ion mass spectrometry of genetically encoded targets. Angewandte Chemie - International Edition 54, 5784-5788

65 Kabatas, S. et al. (2019) Fluorinated nanobodies for targeted molecular imaging of biological samples using nanoscale secondary ion mass spectrometry. Journal of Analytical Atomic Spectrometry 34, 1083-1087

66 Thiery-Lavenant, G. et al. (2014) Detection of immunolabels with multi-isotope imaging mass spectrometry. Surface and Interface Analysis 46, 147-149

67 Angelo, M. et al. (2014) Multiplexed ion beam imaging of human breast tumors. Nature Medicine $20,436-442$

68 Kabatas, S. et al. (2019) Boron-Containing Probes for Non-optical High-Resolution Imaging of Biological Samples. Angewandte Chemie International Edition 58, 3438-3443

69 Ismagulova, T. et al. (2018) A new simple method for quantification and locating $\mathrm{P}$ and $\mathrm{N}$ reserves in microalgal cells based on energy-filtered transmission electron microscopy (EFTEM) elemental maps. PLOS ONE 13, 1-21

70 Yang, Y. et al. (2019) Three-Dimensional Correlative Imaging of a Malaria-Infected Cell with a Hard X-ray Nanoprobe. Analytical Chemistry DOI: 10.1021/acs.analchem.8b05957

71 Dierolf, M. et al. (2010) Ptychographic X-ray computed tomography at the nanoscale. Nature 467, 436-439

2 Victor, T.W. et al. (2018) X-ray Fluorescence Nanotomography of Single Bacteria with a Sub-15 nm Beam. Scientific Reports 8, 1-8

Wirtz, T. et al. (2019) Imaging and Analytics on the Helium Ion Microscope. Annual Review of Analytical Chemistry 12, 523-543

74 Baumeister, T.U.H. et al. (2019) Live single-cell metabolomics with matrix-free laser/desorption ionization mass spectrometry to address microalgal physiology. Frontiers in Plant Science 10, 1-9

Passarelli, M.K. et al. (2017) The 3D OrbiSIMS—label-free metabolic imaging with subcellular 
lateral resolution and high mass-resolving power. Nature Methods DOI: 10.1038/nmeth.4504

60676 Deng, J. et al. (2018) Correlative 3D x-ray fluorescence and ptychographic tomography of frozen607 hydrated green algae. Science Advances 4, 1-11

60877 Deng, J. et al. (2019) The Velociprobe: An ultrafast hard X-ray nanoprobe for high-resolution $609 \quad$ ptychographic imaging. Review of Scientific Instruments 90, 083701

61078 Gibbin, E. et al. (2018) Using NanoSIMS coupled with microfluidics to visualize the early stages 611 of coral infection by Vibrio coralliilyticus. BMC Microbiology 18, 39

61279 Kontziampasis, D. et al. (2019) A cryo-EM grid preparation device for time-resolved structural $613 \quad$ studies. IUCrJ 6, 1024-1031

$61480 \quad$ Heiligenstein, X. et al. (2014) The CryoCapsule: Simplifying Correlative Light to Electron 615 Microscopy. Traffic 15, 700-716

61681 Sigal, Y.M. et al. (2018) Visualizing and discovering cellular structures with super-resolution 617 microscopy. Science 361, 880-887

61882 Ackerman, C.M. et al. (2017) Analytical Methods for Imaging Metals in Biology: From Transition 619

83 Bernhardt, M. et al. (2018) Correlative microscopy approach for biology using X-ray holography, X-ray scanning diffraction and STED microscopy. Nature Communications 9, 1-9 microscopy of amiodarone internalisation by lung macrophages as evidence for drug-induced phospholipidosis. Chemical Communications 53, 1506-1509 